\title{
Allelopathic Potentials of Cuscuta campestris Yuncker Extracts on Germination and Growth of Radish (Raphanus sativus L.) and Lettuce (Lactuca sativa L.)
}

\author{
Muhammad Remy Othman ${ }^{1}$, Sow Tein Leong ${ }^{2}$, Baki Bakar ${ }^{1}$, Khalijah Awang ${ }^{2} \&$ Mohamad Suffian Mohamad \\ Annuar $^{1}$ \\ ${ }^{1}$ Institute of Biological Sciences, University of Malaya, Kuala Lumpur, Malaysia \\ ${ }^{2}$ Department of Chemistry, University of Malaya, Kuala Lumpur, Malaysia \\ Correspondence: Baki Bakar, Institute of Biological Sciences, University of Malaya, 50603 Kuala Lumpur, \\ Malaysia. E-mail: baki.bakar@gmail.com
}

Received: April 9, 2012 Accepted: April 23, 2012 Online Published: July 26, 2012

doi:10.5539/jas.v4n9p57 URL: http://dx.doi.org/10.5539/jas.v4n9p57

\begin{abstract}
Cuscuta campestris Yuncker, commonly known as Golden dodder is an annual problematic parasitic weed in abandoned and derelict areas in Malaysia. The weed is leafless plant, glabrous, yellow-white in colour, with haustoria, sucker-like attachments to the aerial parts of a wide range of host plants. This study was instituted to assess the allelopathic potentials of $C$. campestris on lettuce and radish as test plants. Three types of treatment using aqueous extract of fresh (fc), and dried $s(\mathrm{dc})$ and ethanol extract of dried C. campestris (ec) were assayed for their allelopathic effects on radish (Raphanus sativus) and lettuce (Lactuca sativa) seeds. These extracts reduced seed germination, root and shoot lengths of both radish and lettuce. The roots of radish were more sensitive vis-à-vis the shoots when exposed to fc, while shoots were more sensitive than roots when exposed to dc. Dose-mediated differences in shoot and root lengths of radish were registered when treated with ec. The roots of lettuce were more sensitive compared with the shoots when exposed to ec, while no measurable effect was observed when roots and shoots of lettuce were exposed to fc and dc. The results demonstrated the allelopathic effects of dodder on the tested host plants. The potentials of these extracts and their chemical constituents as bioactive ingredients for new herbicides are implied.
\end{abstract}

Keywords: Allelopathy, Cuscuta campestris, natural herbicides, germination, Raphanus sativus, Lactuca sativa

\section{Introduction}

The term "allelopathy" was first coined by Molisch (1937). Allelopathy involves the release of bioactive compounds or chemicals into the environment by plants or organisms, and their ensuing biochemical activities may affect the growth of other plant species or organism presence in the immediate environment (Rice, 1974 \& 1984), or impacting predators, fungi or bacteria from growing in the area (Putnam, 1988; Rice, 1974). Tesio and Ferrero (2010) showed that allelopathic activity was present in the annual and seasonal weeds, having an impact on agricultural crops especially giving effect by inhibiting the growth and proliferation of plants. Theoretically this allelopathic effect reduced seed germination. The implication of this finding would be extended toits application in commercial agriculture, principally in reducing seed germination of weeds (Singh et al., 2003).

Plant allelopathy is a breakthrough in the field of agricultural science. Allelopathy serves as secondary metabolites, which result from the adaptation process of plants in relation to the hosts. Allelopathy evolution resulting from changes in the plant environment factors such as competition for oxygen, sources of nutrients, space and light has led to the production of secondary metabolites that serve as allelopathy (Inderjit et al., 2011). In addition, there are several types of allelopathy in the form of chemical compounds such as alkaloids, sesqui-and terpenoids, which may serve as protective materials from the animals' herbivora (Macías, 2007). Leslie and Stephen (2003) defined that these activities involved chemical mechanisms. The presence of this mechanism is evident that internal activity also plays a role in the protection of weedy plants.

Weeds population dynamics can be influenced by several inherent factors such as seed dormancy and the prevailing agro-edaphic factors in the habitat (Baki, 2007; Baki et al., 2009). Another pertinent factor that affects plant growth include the presence of allelochemicals and the associated allelopathic activities, and this in turn 
may affect growth in the immediate environment principally in agricultural areas (Parker \& Riches, 1993; Qasem, 2011).

Cuscuta campestris Yuncker, a parasitic weed, has its own functional system of the haustoria to take nutrients from the host plants. The haustoria act as roots transferring nutrients from the host plants to C. campestris. The intricacy of nutrient transfer mechanism via the haustoria in C. campestris from the host plants has led to various studies being conducted to assess and evaluate these special traits (Press \& Graves, 1995; Parker \& Riches, 1993; Press \& Pheonix, 2005).

Weeds population dynamics can be influenced by several inherent factors such as seed dormancy and the prevailing agro-edaphic factors in the habitat (Baki, 2007; Baki et al., 2009). Another pertinent factor that affects plant growth include the presence of allelochemicals and the associated allelopathic activities, and this in turn may affect growth in the immediate environment principally in agricultural areas (Parker \& Riches, 1993; Qasem, 2011).

The principal objective of this study was to assess the allelopathic potentials of water aqueous extracts of fresh and dried C. campestris, and the ethanol extract of dried C. campestris on seed germination and growth of radish (Raphanus sativus L.) and lettuce (Lactuca sativa L.) seedlings.

\section{Materials and Methods}

Plant samples of Cuscuta campestris Yuncker was collected from Pekan Nanas, Johor, Malaysia (N $1^{\circ} 20^{\prime}$ to $\mathrm{N}$ $2^{\circ} 35^{\prime}$ and E $102^{\circ} 28^{\prime} 59.9^{\prime \prime}$ to E $\left.104^{\circ} 33^{\prime} 52.9^{\prime \prime}\right)$. These samples were cleaned of any attached host plant materials followed by washing them with tap water for several times prior to storage in the refrigerator below $20^{\circ} \mathrm{C}$ until use. Three types of treatment were instituted for the purpose of samples preparation and bioassays: (i) water extract of fresh C. campestris (fc), (ii) water extract of dried C. campestris (dc) and (iii) ethanol extract of dried C. campestris (ec). The test plants for the bioassay were radish (Raphanus sativus L.) and lettuce (Lactuca sativa).

\subsection{Preparation of Water Extract of Fresh C. campestris}

A total of $40 \mathrm{~g}$ of fresh C. campestris was cut into small pieces $1-2 \mathrm{~cm}$ and then macerated with a blender. These materials were then soaked in $8 \mathrm{~L}$ of distilled water for $24 \mathrm{~h}$ at $25^{\circ} \mathrm{C}$ in a shaker, and placed on a shaker (Faravani et al. 2008). The mixture was then filtered through four layers of cheesecloth. The supernatant was filtered again using paper "Whatman no. 42 " as a stock solution for water extract of fresh C. campestris $(40 \mathrm{~g} / 8 \mathrm{~L}=5000 \mathrm{ppm})$.

\subsection{Preparation of Water Extract of Dried C. campestris}

About $200 \mathrm{~g}$ of fresh C. campestris was dried in an oven at $40^{\circ} \mathrm{C}$ for $48 \mathrm{~h}$, after dried, take $40 \mathrm{~g}$ of dried were pounded into powdered form, and about $8 \mathrm{~L}$ of distilled water were then added in a conical flask, and left to soak for $24 \mathrm{~h}$. The mixture was then filtered through four layers of cheesecloth. The supernatant was filtered again using paper "Whatman no. 42 " as a stock solution for water extract of dried C. campestris $(40 \mathrm{~g} / 8 \mathrm{~L}=5000 \mathrm{ppm})$.

\subsection{Preparation of Ethanol Extract of C. campestris}

About $200 \mathrm{~g}$ of dried C. campestris samples were placed into a conical flask and was soaked with $95 \%$ of ethanol. The mixture was left to shake for 8 hours, and then left to soak for 3 days. The mixture was filtered with a "Whatman No. 42" filter paper. The filtrate was poured into the smaller round conical flask, and this was used for freed from the solvent under reduced pressure using rotary evaporator with $40^{\circ} \mathrm{C}$ on speed 5 to 6 . The crude was placed in the bottle and was left to evaporate at room temperature. About $5 \mathrm{~g}$ from the crude was adding $1000 \mathrm{ml}$ to become $5000 \mathrm{ppm}$.

\subsection{Bioassays}

Dilutions were made with distilled water to concentrations of $1000 \mathrm{ppm}, 500 \mathrm{ppm}, 200 \mathrm{ppm}$ and 100ppm. Respective controls of 0ppm were prepared likewise for each type of extract. An $8 \mathrm{ml}$ aliquot of the extract was pipetted into each petri-dish that previously lined with a filter paper and sowed with 20 seeds of radish or lettuce. These treatments were place in a growth chamber model $818(230 \mathrm{~V}, 860$ watts) for 7 days. These routines were repeated 3 times for each type of extract. The percentage of seed germination, shoot and root lengths were recorded 7 days after treatment.

\subsection{Analysis}

The data on seed germination, shoot and root lengths of radish and lettuce were subjected to analysis of Variance (ANOVA) and any difference in treatment means were tested with LSD tests at $\mathrm{p}<0.05$ (Zar 2009; Ilori et al. 2010; Omezzine et al. 2011; Shahbaba 2012). 
The shoot and root lengths of treated radish and lettuce seedlings as percentages of the control were tested for growth promotion and inhibition was based on the formula:

$$
\% \text { growth inhibition }=100(p c-p t) / p c
$$

Where $p c$ and $p t$ are the shoot or root lengths of the control and the treated sample, respectively.

\section{Results}

\subsection{Allelopathic Effect of 3 Types of Extracts of Cuscuta campestris on Radish}

The fresh plant extracts of $C$. campestris did not reduce seed germination of radish (Table 1) while, root and shoot lengths were also not affected despite the increase in dose from 100ppm to 5000ppm (Figure 2). In the same vein, exposure to dried plant and ethanol extracts of dodder also failed to register meaningful reductions in seed germination of radish. Albeit differences in the quanta of dose-mediated reductions in shoot growth following exposures to extracts of dried plant samples of $C$. campestris, these reductions were not significant. In contrast, similar exposures to ethanol extracts registered significant dose-mediated reductions in shoot and root growth of radish seedlings, with roots being more sensitive than shoots. Shoots and roots of radish were measurably more sensitive when exposed to ethanol extracts of dried sample with parallel increase in concentrations from 1000ppmto 5000ppm.For example, at the extreme dose of 5000ppm, the shoot length of $11.38 \mathrm{~mm}$ compared with $32.60 \mathrm{~mm}$ of control seedlings of radish. Similarly, the parallel figures for roots were $11.64 \mathrm{~mm}$ (control) against $71.89 \mathrm{~mm}$ (exposed to $5000 \mathrm{ppm}$ ), fortifying the argument that the roots were more sensitive than shoots. Exposures to dried plant extracts of $C$. campestris did not inflict any significant reductions in shoot lengths of radish, even at the extreme does of 5000ppm. On the contrary, a similar exposure has led to erratic dose-mediated reduction, albeit small, in root lengths of radish.

Table 1. Effect of extracts Cuscuta campestris on the germination and growth of radish (Raphanus sativus) seedlings

\begin{tabular}{|c|c|c|c|}
\hline Concentration (ppm) & Germination (\%) & Shoot Length (mm) & Root Length (mm) \\
\hline \multicolumn{4}{|c|}{ Ethanol extract of dried $C$. campestris (ec) } \\
\hline 0 & $100.00 \mathrm{a}(0.00)$ & $32.60 \mathrm{~b}(0.00)$ & $71.89 \mathrm{c}(0.00)$ \\
\hline 100 & $98.33 a(-1.67)$ & $41.24 \mathrm{c}(+8.63)$ & $71.02 \mathrm{c}(-0.88)$ \\
\hline 200 & $98.33 a(-1.67)$ & $40.39 \mathrm{c}(+7.78)$ & $62.17 \mathrm{bc}(-9.72)$ \\
\hline 500 & $100.00 \mathrm{a}(0.00)$ & $29.61 b(-3.00)$ & $52.20 \mathrm{~b}(-19.69)$ \\
\hline 1000 & $100.00 \mathrm{a}(0.00)$ & $15.93 a(-16.67)$ & $16.09 \mathrm{a}(-55.80)$ \\
\hline 5000 & $95.00 \mathrm{a}(-5.00)$ & $11.38 \mathrm{a}(-21.22)$ & $11.64 \mathrm{a}(-60.25)$ \\
\hline \multicolumn{4}{|c|}{ Water extract of dried C. campestris (dc) } \\
\hline 0 & $100.00 \mathrm{a}(0.00)$ & $28.19 \mathrm{abc}(0.00)$ & $68.49 \mathrm{~b}(0.00)$ \\
\hline 100 & $100.00 \mathrm{a}(0.00)$ & $24.67 \mathrm{a}(-3.52)$ & $52.87 \mathrm{a}(-15.63)$ \\
\hline 200 & $98.33 a(-1.67)$ & $28.64 \mathrm{bc}(+0.46)$ & $67.16 \mathrm{~b}(-1.33)$ \\
\hline 500 & $96.67 \mathrm{a}(-3.33)$ & $30.15 b c(+1.96)$ & $63.52 b(-4.97)$ \\
\hline 1000 & $96.67 \mathrm{a}(-3.33)$ & $27.47 \mathrm{ab}(-0.71)$ & $60.84 \mathrm{ab}(-7.65)$ \\
\hline 5000 & $98.33 a(-1.67)$ & $31.61 \mathrm{c}(+3.42)$ & $52.28 \mathrm{a}(-16.21)$ \\
\hline \multicolumn{4}{|c|}{ Water extract of fresh $C$. campestris (fc) } \\
\hline 0 & $100.00 \mathrm{a}(0.00)$ & $28.19 \mathrm{ab}(0.00)$ & $68.49 \mathrm{a}(0.00)$ \\
\hline 100 & $96.67 \mathrm{a}(-3.33)$ & $26.86 \mathrm{a}(-1.33)$ & $62.67 \mathrm{a}(-5.82)$ \\
\hline 200 & $100.00 \mathrm{a}(0.00)$ & $29.27 \mathrm{ab}(+1.08)$ & $69.85 \mathrm{a}(+1.36)$ \\
\hline 500 & $98.33 a(-1.67)$ & $27.09 \mathrm{a}(-1.10)$ & $69.19 \mathrm{a}(+0.70)$ \\
\hline 1000 & $100.00 \mathrm{a}(0.00)$ & $27.51 \mathrm{ab}(-0.68)$ & $67.70 a(-0.79)$ \\
\hline 5000 & $100.00 \mathrm{a}(0.00)$ & $30.33 b(+2.14)$ & $66.24 \mathrm{a}(-2.25)$ \\
\hline
\end{tabular}

Values in a column with the same lowercase letters are not significantly different at $p<0.05$.(LSD tests)

Values in parentheses indicate growth synergism (positive values) or antagonism (negative values) vis-à-vis the control. 


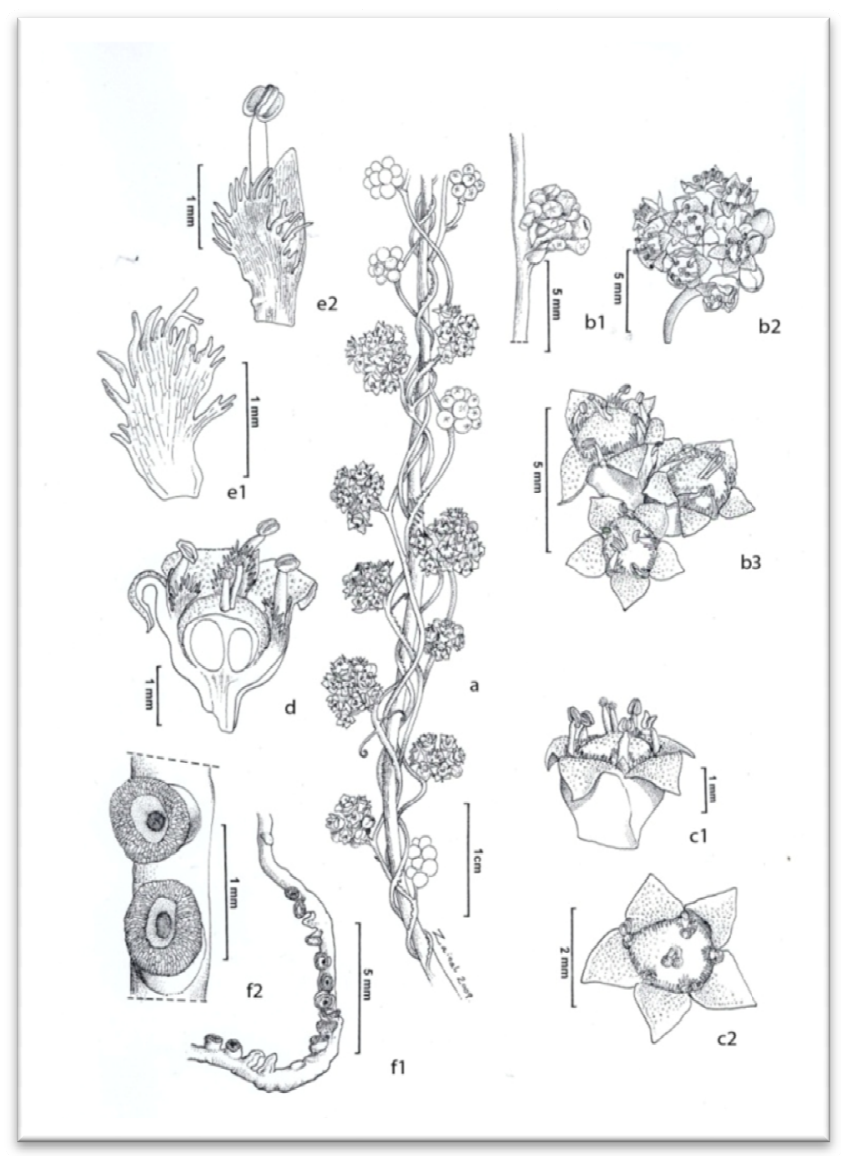

Figure 1. Cuscuta campestris Yuncker. (a) flowering branch, (b1) detail of inflorescence, (b2) floral cluster, (b3) top-view of a cluster of three flowers. (c1) side-view of a flower, (c2) top-view of a flower showing exposed stigmas and stamens, (d) flower, longitudinal section, (e1, e2), appendage enveloping pollen tube, (f1) branch with haustoria, and (f2) closer-view of haustoria

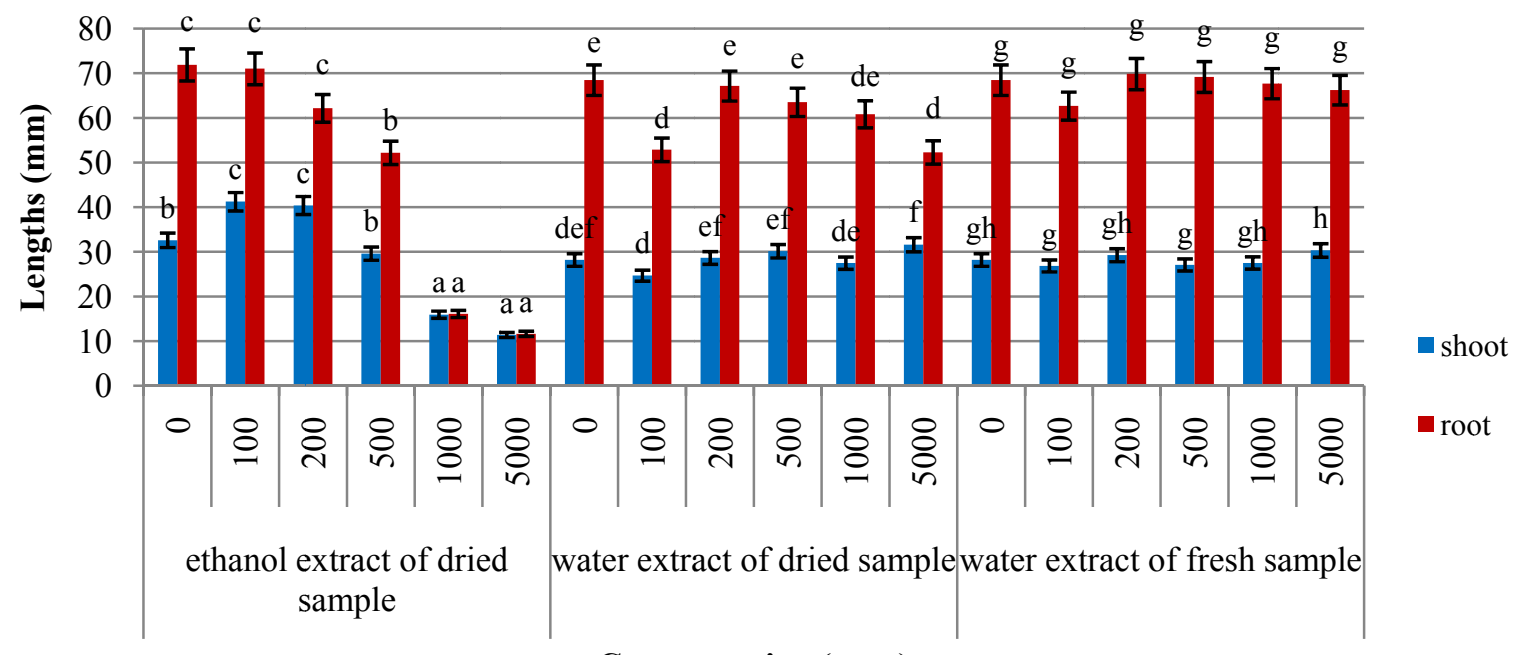

\section{Concentration (ppm)}

Figure 2. Shoot and root lengths of radish when exposed to different concentrations of 3 types extracts of $C$. campestris. Values with different lowercase letters denote significant difference as determined by LSD test at $p<$ 


\subsection{Allelopathic Effect of 3 Types of Extracts of Cuscuta campestris on Lettuce}

The fresh and dried plant, and ethanol extracts of $C$. campestris failed to reduce seed germination of lettuce. The only exception was the exposure to 5000ppm of ethanol extracts of $C$. campestris which registered measurable and significant reduction in seed germination compared to the control (Table 2, Figure 3). The roots and shoots of lettuce showed a significant reduction in lengths following exposure to ethanol extracts of dodder starting at $200 \mathrm{ppm}$ similar to those registered in radish. The lengths of lettuce shoots were very much affected by the ethanol extracts of $C$. campestris at 5000ppm concentration of but showed reduction in root lengths at 500ppm and beyond. Invariably, the roots of lettuce displayed enhanced growth after being exposed to ethanol plant extracts of dodder ranging from $100 \mathrm{ppm}$ to $200 \mathrm{ppm}$. Thereafter, meaningful dose-dependent reductions in root lengths were observed. There were erratic responses following exposures to various doses of fresh and dried plant extracts of dodder in the root lengths of lettuce. The shoots of lettuce were more sensitive to exposures to fresh, dried or ethanol plant extracts of dodder compared to roots. However, the dose-mediated responses following exposures to those extracts were not clearly displayed.

Table 2. Effect of extracts Cuscuta campestris on the germination and growth of lettuce (Lactuca sativa) seedlings

\begin{tabular}{|c|c|c|c|}
\hline Concentration (ppm) & Germination (\%) & Shoot Length (mm) & Root Length (mm) \\
\hline \multicolumn{4}{|c|}{ Ethanol extract of dried $C$. campestris (ec) } \\
\hline 0 & $100.00 \mathrm{~b}(0.0)$ & $10.04 \mathrm{~b}(0.0)$ & $39.28 \mathrm{~d}(0.00)$ \\
\hline 100 & $100.00 \mathrm{~b}(0.0)$ & $13.96 \mathrm{c}(+3.91)$ & $57.81 \mathrm{f}(+18.53)$ \\
\hline 200 & $100.00 \mathrm{~b}(0.0)$ & $13.02 \mathrm{c}(+2.98)$ & 44.70 e $(+5.41)$ \\
\hline 500 & $98.33 \mathrm{~b}(-1.67)$ & $12.36 \mathrm{bc}(+2.32)$ & 22.37 c $(-16.91)$ \\
\hline 1000 & $100.00 \mathrm{~b}(0.0)$ & $12.46 \mathrm{bc}(+2.42)$ & $11.16 \mathrm{~b}(-28.12)$ \\
\hline 5000 & 55.00 a $(-45.00)$ & $1.11 \mathrm{a}(-8.94)$ & 1.86 a $(-37.42)$ \\
\hline \multicolumn{4}{|c|}{ Water extract of dried $C$. campestris (dc) } \\
\hline 0 & $100.00 \mathrm{a}(0.0)$ & $4.869 \mathrm{ab}(0.0)$ & $26.339 b c(0.0)$ \\
\hline 100 & $100.00 \mathrm{a}(0.0)$ & $5.08 \mathrm{ab}(+0.21)$ & $23.591 b c(-2.75)$ \\
\hline 200 & $100.00 \mathrm{a}(0.0)$ & $4.728 \mathrm{a}(-0.14)$ & $29.073 b c(+2.73)$ \\
\hline 500 & $98.33 \mathrm{a}(-1.67)$ & $4.583 a(-0.29)$ & $30.203 c(+3.86)$ \\
\hline 1000 & $98.33 a(-1.67)$ & $4.557 \mathrm{a}(-0.31)$ & $22.392 b(-3.95)$ \\
\hline 5000 & $96.67 \mathrm{a}(-3.33)$ & $5.507 \mathrm{~b}(+0.64)$ & $10.031 \mathrm{a}(-16.31)$ \\
\hline \multicolumn{4}{|c|}{ Water extract of fresh $C$. campestris (fc) } \\
\hline 0 & $100.00 \mathrm{a}(0.0)$ & $5.90 \mathrm{ab}(0.0)$ & $17.90 \mathrm{ab}(0.0)$ \\
\hline 100 & $98.33 a(-1.67)$ & $4.90 \mathrm{a}(-1.00)$ & $23.34 \mathrm{c}(+5.44)$ \\
\hline 200 & $98.33 a(-1.67)$ & $5.46 \mathrm{ab}(+0.438)$ & $17.88 \mathrm{ab}(-0.02)$ \\
\hline 500 & $100.00 \mathrm{a}(0.0)$ & $6.06 \mathrm{~b}(+0.165)$ & $20.22 b c(+2.32)$ \\
\hline 1000 & $100.00 \mathrm{a}(0.0)$ & $5.82 \mathrm{ab}(-0.08)$ & $21.27 \mathrm{bc}(+3.365)$ \\
\hline 5000 & $98.33 a(1.67)$ & $7.90 \mathrm{c}(+2.003)$ & $13.85 a(-4.047)$ \\
\hline
\end{tabular}

Values in a column with the same lowercase letters are not significantly different at $p<0.05$. (LSD tests)

Values in parentheses indicate growth synergism (positive values) or antagonism (negative values) vis-à-vis the control. 


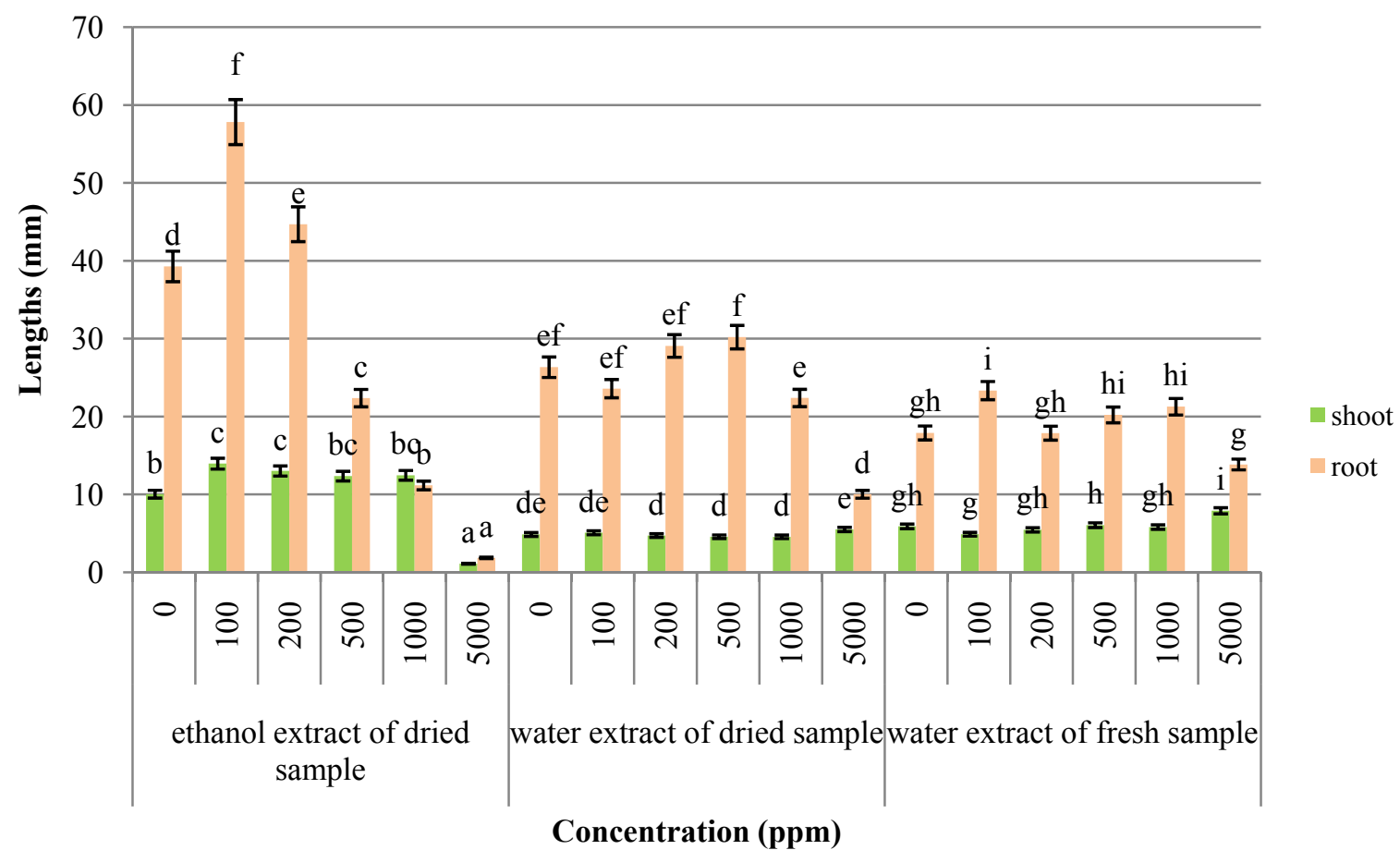

Figure 3. Shoot and root lengths of lettuce when exposed to different concentrations of 3 types extracts of $C$. campestris. Values with different lowercase letters denote significant difference as determined by LSD test at $p<$ 0.05

\section{Conclusions}

This study revealed the potential of dodder's extract as a potential bioherbicide. Despite erratic responses to the three different types of extracts of $C$. campestris, there was a general trend of dose-mediated deleterious effects on the growth of seedlings of the test plants, and in this case of lettuce and radish. However, growth enhancement of shoots of radish seedlings following exposures to $100-200 \mathrm{ppm}$ of ethanol extracts of dodder, fortifying the argument that these extracts can act as growth-promoting substances. There is a promotion or encouragement over the control of elongation occurs (refer Tables 1 and 2). The extracts may contain a lot of water, as can be seen in the non-deleterious effects of the extracts of fresh and dried plant materials of dodder on germination of radish and lettuce, registering almost $100 \%$ germination. Seed germination of radish was inhibited by the ethanol extracts of dodder in excess of 5000ppm, while the growth of radish and lettuce seedlings as test plants were inhibited by dodder's ethanol extracts in excess of 200ppm.In fact, several previous studies have been carried out had proved that certain types of weeds can be slowed or inhibited the growth by using aqueous extracts allelopathic plant samples (Khanh et al.2008; Macías 2007; Omezzine et al. 2011; Yu et al. 2011). Khanh (2008) suggested that allelochemicals from parasitic plants, including Cuscuta spp. might be useful for the development of bioactive pesticides in the future. Further, this study also proves that there are allelochemicals in Cuscuta campestris and many Cuscuta spp. inhibited the growth and the germination of seeds, including weeds that can influence plant population density (Yu et al. 2011).

\section{References}

Baki, B. B., Remy, M. O., Aini, H., Khalijah, A., Fujii, Y., Annuar, M. S. M., \& Zazali, A. (2009). Distribution patterns, host status and damage susceptibility of crops plants and weed species to CuscutacampestrisYuncker in Malaysia. Korean Journal of Weed Science, 29(3), 185-193.

Baki, H. B. (2007). Utilization of Weeds and Their Relatives; Malaysia Perspective. In Utility of Weeds and Their Relatives as Resources. (Kim K.U., Shin D.H., Lee I.J., eds.). Kyungpook National University, Korea, pp. 57-106.

Faravani, M., Baki H. B., \& Khalijah A. (2008). Assessment of Allelopathic Potential of Melastoma malabrathicum L. on Radish (Raphanus sativusL). and Barnyard Grass (Echinochloa crus-galli). Notulae 
Botanicae Horti Agrobotanici Cluj-Napoca, 36(2), 54-60. Retrieved from http://notulaebotanicae.ro/nbha/article/view/69

Ilori, O. J., Otusanya, O. O., Adelusi, A. A., \& Sanni, R. O. (2010). Allelopathic Activies of Some Weeds in the Asteraceae Family. International Journal of Botany, 6(2), 161-163. http://dx.doi.org/docsdrive.com/pdfs/ansinet/ijb/2010/161-163.pdf

Inderjit, Wardle, D. A., Karban, R., \& Callaway, R. M. (2011). The ecosystem and evolutionary contexts of allelopathy. Trends in Ecology and Evolution, 26(12), 655-662. http://dx.doi.org/10.1016/j.tress.2011.08.003

Khanh, T. D., Cong, L. C., \& Xuan, T. D. (2008). Weed-Suppressing Potential of Dodder (Cuscuta hygrophilae) and its Phytotoxic Constituents. Weed Science, 56(1), 119-127. http://dx.doi.org/10.1614/WS-07-102.1

Leslie, A. W. \& Stephen O. D. (2003). Weed and Crop Allelopathy. Critical Review in Plant Sciences, 22(3), 367-389. http://dx.doi.org/10.1080/713610861

Macías, F. A., Molinillo, J. M., Varela, R. M., \& Galindo, J. C. (2007). Allelopathy-a natural alternative for weed control. Pest Management Science, 63(4), 327-348. http://dx.doi.org/10.1002/ps. 1342

Molisch, H. (1937). Der Einfluss eine Pflanze auf die andere: Allelopathie. Gustav Fischer, Jena.

Omezzine, F., Ladhari, A., Rinez, A., \& Haoulala, R. (2011). Potent herbicidal activity of Inula crithmoides L. Scientia Horticulturea, 130(4), 853-861. http://dx.doi.org/10.1016/j.scienta.2011.08.013

Parker, C., \& Riches, C. R. (1993).Cuscuta species, the dodders; and Cassytha filformis. In Parasitic Weeds of the Worlds: Biology and Control. CAB International, Wallingford, UK, (pp. 183-223).

Press, M. C., \& Graves, J. D. (1995). Parasitic Plants. Chapman \& Hall, London, (pp. 39-73).

Press, M. C., \& Pheonix, G. K. (2005). Impacts of parasitic plants on natural communities. New Phytologist, 166(3), 37-751. http://dx.doi.org/10.1111/j.1469-8137.2005.01358.x

Putnam, A. R. (1988). Allelochemicals from plants as herbicides. Weed Technology, 2(4), 510-518. Retrieved fromhttp://www.jstor.org/discover/10.2307/3987390?uid=3738672\&uid=2134\&uid=2\&uid=70\&uid=4\&si $\mathrm{d}=47699006275997$

Qasem, J. R. (2011). Parasitic flowering plants of woody species in Jordan. European Journal of Plant Pathology, 131(1), 143-155. http://dx.doi.org/10.1007/s10658-011-9794-2

Rice, E. L. (1984). Allelopathy. Second Edition Academic Press Inc. The University of Okalahoma. Norman Oklahoma.

Rice, E. L. (1974). Allelopathy. Academic Press, New York.

Shahbaba, B. (2012). In Biostatistics with R, An Introduction to Statistics Through Biological Data, (pp. 221-234). http://dx.doi.org/10.1007/978-1-4614-1302-8_9

Singh, H. P., Batish, D. Z., \& Kohli, R. K. (2003). Allelopathic Interactions and Allelochemicals: New Possibilities for Sustainable Weed Management. Critical Review in Plants Sciences, 22(3-4), 239-311. http://dx.doi.org/10.1080/713610858

Tesio, F., \& Ferrero, A. (2010). Allelopathy, a chance for sustainable weed management. International Journal of Sustainable Development \& World Ecology, http://dx.doi.org/10.1080/13504509.2010.507402

Yu, H., Liu, J., He, W. M., Mioa, S. L., \& Dong, M. (2011). Cuscuta australis restrains three exotic invasive plants and benefits native species. Biological Invasions, 13(3), http://dx.doi.org/10.1007/s10530-010-9865-x

Zar, J. H. (2009). Biostatistical Analysis. Prentice-Hall. Englewood Cliffs, New Jersey. 